\title{
Iron state and hepatic disease in patients with thalassaemia major, treated with long term subcutaneous desferrioxamine
}

\author{
M A ALDOURI, ${ }^{*}$ BEATRIX WONKE, $\dagger$ A V HOFFBRAND,* D M FLYNN, \\ MARTINE LAULICHT,* L A FENTON, $\uparrow$ P J SCHEUER, C C KIBBLER, $\dagger$

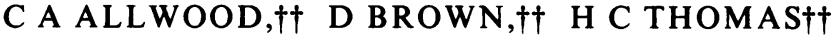

From the Departments of ${ }^{*}$ Haematology, $\ddagger$ Paediatrics, $\uparrow$ Histopathology, and $\dagger \dagger$ Medicine, Royal Free Hospital and School of Medicine, London, and the †Department of Haematology, Whittington Hospital, London

SUMMARY Liver biopsies were performed on 51 regularly transfused patients with $\beta$ thalassaemia, age range 5-36 (mean 18.6) years, who had received regular subcutaneous desferrioxamine (DFX) treatment for periods between one and eight years (40 for eight years). The biopsy specimens were examined by light microscopy and immunofluorescence for hepatitis B virus surface and core antigens ( $\mathrm{HBsAg}$ and $\mathrm{HBcAg}$ ), and the iron content was determined chemically. The results were compared with serum ferritin concentration and aspartate transaminase (AST) activity and with hepatitis B virus serology. Biopsy specimens, in which chemical liver iron had been determined in 12, were also available from 17 patients. Mean serum ferritin ( \pm SD) had fallen from 5885 (3245) $\mu \mathrm{g} / 1$ to $1638(976) \mu \mathrm{g} / 1$ in 36 patients after eight years' chelation, while mean $( \pm \mathrm{SD})$ liver iron concentration had fallen from 2945 (900) $\mu \mathrm{g} / 100 \mathrm{mg}$ dry weight to 857 (435) $\mu \mathrm{g} / 100 \mathrm{mg}$ dry weight in 12 of them. All biopsy specimens examined were negative for $\mathrm{HBs}$ and $\mathrm{HBc}$ antigens. The presence of histological features of hepatitis was associated with increased liver iron content, increased fibrosis, and with progression of fibrosis between the two biopsies. Procollagen III peptide was assayed in 28 patients but did not correlate with the degree of hepatitis, fibrosis, or with chemical liver iron content. We conclude that with regular subcutaneous DFX, mean concentrations of serum ferritin and liver iron are maintained in these patients at about five and 10 times the normal value, respectively, and that progression of liver damage is more likely to be due to viral hepatitis, presumably related to the parenterally transmitted non-A, non-B agents than to iron overload.

Liver damage in regularly transfused patients with $\beta$ thalassaemia major results from increased hepatic iron content and chronic hepatitis associated with transfusion. ${ }^{1-5}$ Regular chelation with subcutaneous desferrioxamine (DFX) has been shown to produce negative iron balance in these patients with or without hepatitis. ${ }^{6-11}$ On the other hand, hepatitis after transfusion remains a common complication which contributes to progressive liver damage. In this study we performed liver biopsies on 51 such patients receiving regular blood transfusions who had also received subcutaneous DFX for periods from one to eight years to determine the extent of liver damage and assess the value of serum ferritin concentrations and aspartate transaminase (AST) activity as indi-

Accepted for publication 27 May 1987 cators of liver iron content and liver damage, respectively. We also investigated a possible association between serum concentrations of procollagen type III peptide synthesis and liver disease.

\section{Patients and methods}

Liver biopsies were performed on 51 patients (22 females, 29 males, aged 8-36 (mean 18.6) years with $\beta$ thalassaemia major, who had received blood transfusions every four to five weeks for four to 34 (mean 16.5) years to maintain a pre-transfusion haemoglobin above $10.5-11 \mathrm{~g} / \mathrm{dl}$. Forty patients had received subcutaneous chelation for eight years, four for six years, and seven for one to five years. The biopsy was performed to determine the extent of liver damage and liver iron overload. Informed consent 
was obtained from each patient. Thirty four patients $(66.7 \%)$ had received transfusions only in the United Kingdom. Most also received subcutaneous chelation with DFX $40-60 \mathrm{mg} / \mathrm{kg}$ on five to six nights each week. A few poorly compliant patients used infusions less often (two to four times weekly). The biopsies were performed using standard Menghini needles, except in two patients who had wedge biopsy of the liver when their spleens were removed. There were no complications related to the biopsies.

Each biopsy sample was divided into three parts for determination of chemical liver iron content, detection of hepatitis B antigens, and for histology. The specimens were analysed for chemical liver iron using the method described by Barry and Sherlock ${ }^{12}$ (normal range 35-136 $\mu \mathrm{g} / 100 \mathrm{mg}$ dry weight). The presence of $\mathrm{HbsAg}$ and $\mathrm{HBcAg}$ in the biopsy specimens was investigated using immunofluorescence. Briefly, fresh liver tissue was snap frozen in OCT embedding compound and kept in liquid nitrogen until analysed. Sections $(4 \mu \mathrm{m})$ were cut on to glass slides, dried under a fan for one hour, and fixed in cold acetone. The sections were washed in phosphate buffer saline (PBS) and then for 20 minutes with the appropriate dilutions of murine monoclonal antibodies to either $\mathrm{HBsAg}$ or $\mathrm{HBcAg}$ (raised in our laboratories). Normal mouse serum was used as negative control. The sections were incubated at room temperature for 30 minutes and then washed in PBS for 20 minutes. Fluorescent rabbit antiserum to mouse immunoglobulin (Dako Ltd, High Wycombe) was then added to each section and incubated at room temperature for 30 minutes and mounted under a coverslip in $50 \%$ glycerol in PBS. They were then viewed under ultraviolet light illumination on a Leitz Dialux 20 microscope.

\section{HISTOLOGICAL ASSESSMENT}

The specimens were assessed on several occasions by one histopathologist and finally reviewed by another. Samples obtained for histological assessment were adequate in most cases. There was homogeneous distribution of iron and inflammatory cells in both the percutaneous and wedge biopsy specimens., Fibrosis was also assessed. Degree of siderosis in hepatocytes, Kupffer cells, and endothelial cells was graded from $0-4$, as shown by Perls's stain; grade 1 representing minimal amounts, and grade 4 the degree seen in hepatocytes in fully developed untreated haemochromatosis. Features of hepatitis were also classified into five grades: grade 0 , no evidence of hepatitis; grade 1 , scanty lymphocytic infiltrate; grade 2 , obvious inflammatory cell infiltrate in the portal tracts and lobules with little or no liver damage; grade 3, lobular component and evidence of liver cell damage (acidophil bodies or piecemeal necrosis); grade 4 , severe inflammatory infiltrate and liver cell damage. This method of grading was chosen rather than the more conventional classification of chronic persistent and chronic active hepatitis, because in our experience progression of liver disease in thalassaemic patients seemed to be mainly by portal fibrosis and focal lobular inflammation and necrosis rather than by piecemeal necrosis, the defining feature of chronic active hepatitis. Fibrosis was graded as follows: 0, no fibrosis; 1, portal expansion; 2 , septum formation; 3 , linking of portal tracts or perilobular fibrosis; 4 , cirrhosis.

Serum ferritin was measured by immunoradiometric assay ${ }^{13}$ before and during subcutaneous chelation. The normal ranges for our laboratories are 39-340 $\mu \mathrm{g} / 1$ in males and $14-148 \mu \mathrm{g} / 1$ in females. Serum AST was measured throughout the study at intervals of three months or less. Normal values are less than $40 \mathrm{IU} / 1$. Serological tests were carried out to determine the hepatitis B virus state of each patient. The immunoradiometric assay of Goodall et $\mathbf{a l}^{14}$ for HBsAg was used. Total antibodies to HBsAg, $\mathrm{ABcAg}$, and $\mathrm{HBeAg}$ were measured using commercially available kits (Abbot Laboratories, Diagnostic Division).

Procollagen type III peptide is a biosynthetic precursor of collagen type III and was measured in serum as a possible indicator of the degree of hepatic fibrosis in these patients. The method used was a radioimmunoassay using an RIA-ghost kit (Behringwerkeo AG, Marburg, West Germany).

Current AST and serum ferritin results were compared with those before starting subcutaneous chelation. Liver biopsy specimens had been performed on 17 patients before chelation began, with chemical liver iron content measured in 12.

Statistical analysis was carried out by the KruskalWallis and Mann-Whitney analyses for nonparametric studies comparing histological and chemical results, and linear regression analysis for correlating serum ferritin, chemical liver iron content, and AST. The Wilcoxon rank sum test for paired samples was used to compare changes in serum ferritin and chemical liver iron after eight years of chelation.

\section{Results}

SERUM FERRITIN AND CHEMICAL LIVER IRON All 51 patients showed raised serum ferritin concentrations ranging from 340-6500, mean (SD) 1740 (1330) $\mu \mathrm{g} / 1$, and mean (SD) chemical liver iron concentrations in 44 patients ranged from $68-6500,1390$ (1558) $\mu \mathrm{g} / 100 \mathrm{mg}$ dry weight. Only two patients, both aged 8 years who had been chelated from the start of transfusions, had normal chemical liver iron concentrations. 
LIVER HISTOLOGY (table 1)

Siderosis Most patients showed grades 2 or 3 siderosis in hepatocytes, Kupffer, and endothelial cells; a few had no excessive iron visible; some showed grade 4 siderosis (table 1 ).

Hepatitis All the patients showed some features of hepatitis although this was minimal (grade 1) in 21 patients. None showed grade 4 features, but $19(37 \%)$ showed grade 3 features.

Fibrosis All but six of the patients showed some increase in fibrosis and in five cirrhosis was fully developed.

The chemical liver iron concentrations of patients with grades $0, \overrightarrow{1}$, or 2 hepatocyte siderosis were not significantly different from each other (fig 1). The chemical liver iron of patients with grades 0,1 , and 2 hepatocyte siderosis, however, was significantly less than that of patients with grades $3(p=0.01)$ and 4 $(p<0.001)$ hepatocyte siderosis. There was also a significant difference between the chemical liver iron of patients with grades 3 and 4 siderosis $(p<0.04)$. Hepatocyte siderosis correlated slightly better with chemical liver iron content than did the degree of endothelial and Kupffer cell siderosis.

In the whole group there was a good correlation between serum ferritin and chemical liver iron content $(r=0.886, p<0.0001$ (fig 2). We found a closer correlation between serum ferritin concentration and chemical liver iron content in patients with grades 1 and 2 hepatitis $(r=0.963)$ than in patients with grade 3 hepatitis $(r=0.775)$. The mean chemical liver iron content in the patients with severe (grade 3 ) hepatitis (mean 2331) (1818) $\mu \mathrm{g} / 100 \mathrm{mg}$ dry weight) was significantly higher than that in the group with mild (grades 1 and 2) hepatitis (mean 950 (1219) $\mu \mathrm{g} / 100 \mathrm{mg}$ dry weight $)(p=0.005)$. Mean serum ferritin was also higher in the group with severe hepatitis (2433 (1512) $\mu \mathrm{g} / \mathrm{l})$ compared with (1429 (1252) $\mu \mathrm{g} / \mathrm{l})$ in the group with mild hepatitis $(p=0.025)$, but there was no significant difference between the two groups in the number of units transfused $(p>0.05)$.

\section{RELATION BETWEEN HEPATIC FIBROSIS AND} AGE, CHEMICAL LIVER IRON CONTENT, OR HEPATITIS

Patients with minimal fibrosis (grades 0,1 ) were significantly younger (mean age $14 \cdot 2$ years) than those with moderate or severe fibrosis (grades 2, 3, and 4) (mean age 20.6 years) $(p=0.003)$ (table 2$)$. Liver iron content of patients with minimal fibrosis (grades 0,1 ) was significantly less than in those with severe fibrosis (grades 3,4$)(p<0.03)$. Liver iron content in patients with grades 0 and 1 fibrosis was not significantly different from that of patients with moderate fibrosis (grade 2) $(p>0 \cdot 1)$ nor was there a difference between patients with moderate and severe fibrosis $(p>0.3)$ (fig 3). On the other hand, there was a significant overall correlation between degree of hepatic fibrosis and the severity of hepatitis $\left(\chi^{2}=22.8, p=0.0001\right)$ (fig 4).

AST was raised in $29(37 \%)$ of the 51 patients.

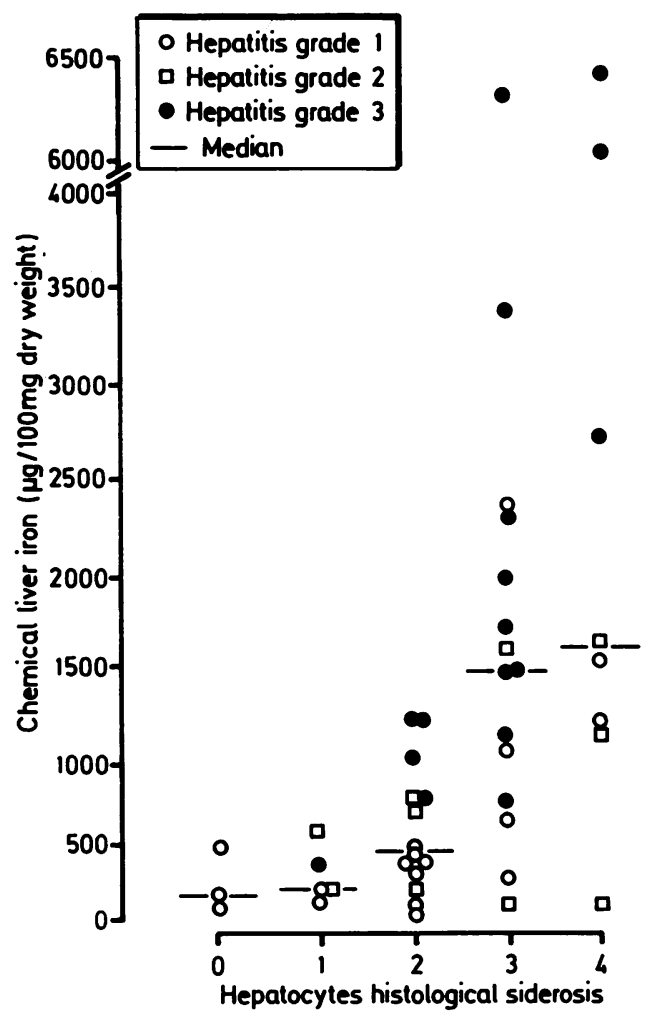

Fig 1 Relation between chemical and histological liver iron content and hepatitis.

Table 1 Grade of siderosis, hepatitis, and fibrosis in 51 patients studied

\begin{tabular}{|c|c|c|c|c|c|c|}
\hline \multirow[b]{2}{*}{ Liver histology } & \multicolumn{6}{|c|}{ Grade } \\
\hline & 0 & 1 & 2 & 3 & 4 & Total \\
\hline $\begin{array}{l}\text { Siderosis: } \\
\text { Hepatocytes } \\
\text { Kupffer cells } \\
\text { Endothelial cells } \\
\text { Hepatitis } \\
\text { Fibrosis* }\end{array}$ & $\begin{array}{l}5 \\
5 \\
1 \\
0 \\
6\end{array}$ & $\begin{array}{r}6 \\
1 \\
3 \\
21 \\
6\end{array}$ & $\begin{array}{l}15 \\
18 \\
19 \\
11 \\
16\end{array}$ & $\begin{array}{l}17 \\
16 \\
23 \\
19 \\
16\end{array}$ & $\begin{array}{r}8 \\
11 \\
5 \\
0 \\
5\end{array}$ & $\begin{array}{l}51 \\
51 \\
51 \\
51 \\
49\end{array}$ \\
\hline
\end{tabular}

*Not evaluable in two patients. 


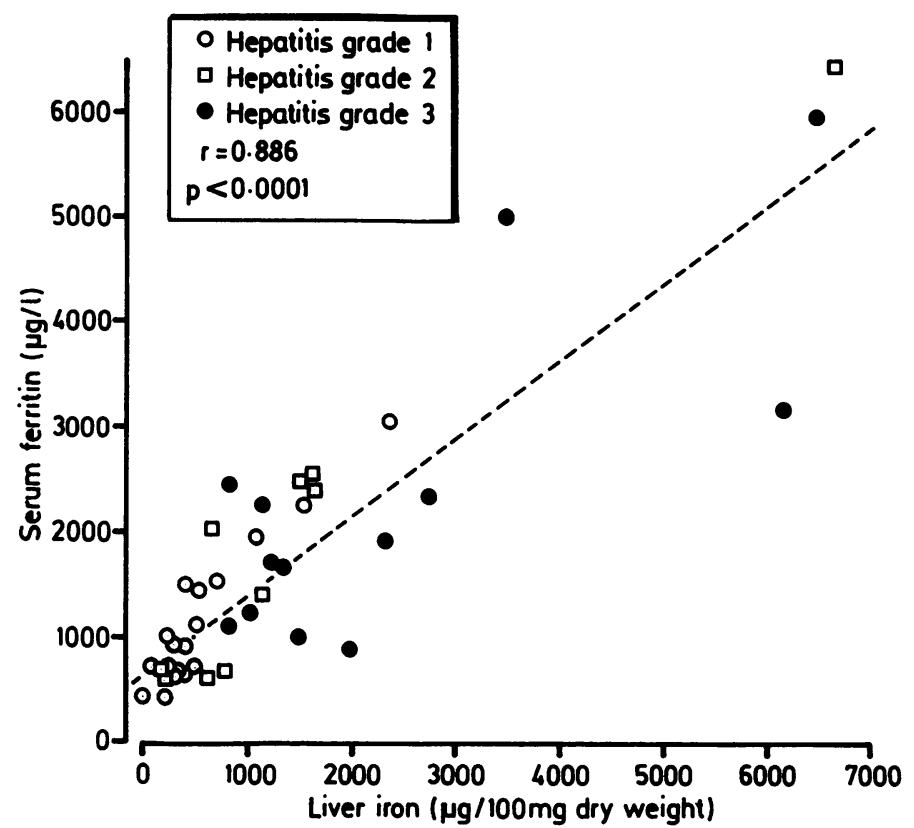

Fig 2 Relation between serum ferritin concentration and chemical liver iron content.

There were poor correlations between serum AST and the serum ferritin $(r=0.283, p=0.06)$ or between serum AST and liver iron content $(r=0.136$, $\mathrm{p}=0 \cdot 384$ ). On the other hand, serum AST correlated well with degree of hepatitis assessed histologically in that all the patients with no evidence of hepatitis or with grade 1 hepatitis showed normal AST values whereas 19 of 30 patients with moderate or severe hepatitis had raised AST values $(\mathrm{p}<0.01)$ (table 3$)$. Indeed, nine patients with grade 3 hepatitis showed AST values more than twice the normal range for periods longer than six months. Nevertheless, interestingly, some patients with moderate or severe hepatitis assessed histologically (grades 2 and 3 ) had normal serum AST values.

Twenty $(39 \%)$ of the 51 patients were serum $\mathrm{HbsAb}$ positive, 12 of whom were also $\mathrm{HBcAb}$ positive. Table 4 shows the relation between hepatitis B virus serology and histological grade of hepatitis. Only four of $21(19 \%)$ patients with grade 1 hepatitis were $\mathrm{HBsAb}$ positive compared with 16 of $30(53 \%)$ with grades 2 and 3 hepatitis. Of 34 patients who re ceived transfusions entirely in the United Kingdom, eight $(23.5 \%)$ had positive $\mathrm{HBsAb}$ or $\mathrm{HBcAb}$, or +

Table 3 Relation of abnormal serum AST to histological grade of hepatitis

\begin{tabular}{lll}
\hline Hepatitis grade & No of patients & Abnormal serum AST \\
\hline $0-1$ & 21 & 0 \\
2 & 11 & 4 \\
3 & 19 & 15 \\
\hline
\end{tabular}

Table 4 Relation between Hbs Ab and histological evidence of hepatitis

\begin{tabular}{lcc}
\hline Histological hepatitis grade & HBs Ab positive & HBs AB negative \\
\hline 1 & 4 & 17 \\
2 & 5 & 5 \\
3 & 11 & 9 \\
\hline
\end{tabular}

Table 2 Relation of grade of hepatic fibrosis to incidence of severe hepatitis (grade 3) in 49 patients

\begin{tabular}{|c|c|c|c|}
\hline Fibrosis grade & No of patients & Age (years) range (mean) & No $(\%)$ with severe hepatitis \\
\hline $\begin{array}{l}0 \\
1 \\
2 \\
3 \\
4\end{array}$ & $\begin{array}{r}6 \\
6 \\
16 \\
16 \\
5\end{array}$ & $\begin{array}{c}8-20(14 \cdot 3) \\
8-17(14) \\
5-29(20 \cdot 6) \\
12-36(20 \cdot 6) \\
11-28(20 \cdot 6)\end{array}$ & $\begin{array}{l}0 \\
0 \\
3(19) \\
10(63) \\
5(100)\end{array}$ \\
\hline
\end{tabular}


both, compared with $12(70.6 \%)$ of 17 transfused outside the United Kingdom in areas medium or panendemic for hepatitis B virus (Greece, Cyprus, Middle East and India). All liver biopsy specimens were negative for $\mathrm{HBs}$ and $\mathrm{HBc}$ antigens by immunofluorescence. Serum procollagen III peptide concentration was measured in 28 patients: it was raised in $14(50 \%)$ but did not correlate with degree of hepatitis, fibrosis, or chemical liver iron, or with serum AST.

\section{FOLLOW UP STUDIES}

The mean serum ferritin concentration in 38 patients had dropped from $5885(3245) \mu \mathrm{g} / \mathrm{l}$ to $1638(976) \mu \mathrm{g} / \mathrm{l}$ ( $p<0.0001)$ after eight years' subcutaneous DFX chelation. Mean chemical liver iron content in 12 patients had dropped from 2945(900) to $857(435) \mu \mathrm{g} / 100 \mathrm{mg}$ dry weight $(\mathrm{p}<0.01)$ after five to eight years on the same treatment (fig 5). Abnormal serum AST was defined as an AST activity above the normal range for a period of six months at the start of subcutaneous DFX or at the time of this study. The AST activity remained normal in $10(28 \%)$ and had improved in $18(50 \%)$ of 36 tested. It deteriorated in four $(11 \%)$ and remained abnormal in a further four $(11 \%)$, all eight of whom had shown severe siderosis and hepatitis (table 5).

Previous biopsy specimens performed six to eight years ago were available from 17 patients. In 11 pa-

Table 5 AST changes in relation to histological evidence of hepatitis and siderosis in 36 patients after eight years of subcutaneous chelation

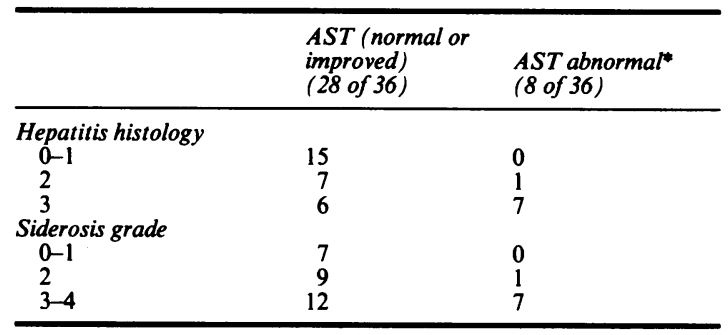

*Abnormal = remained abnormal or became abnormal.

Table 6 Details of five patients with progression of fibrosis

\begin{tabular}{|c|c|c|c|c|c|c|c|}
\hline Sex & Age & Date & $\begin{array}{l}\text { Serum ferritin } \\
(\mu g / l)\end{array}$ & $\begin{array}{l}\text { Chemical liver iron content } \\
(\mu \mathrm{g} / 100 \mathrm{mg} \text { dry weight })\end{array}$ & $\begin{array}{l}A S T \\
(I U / l)\end{array}$ & $\begin{array}{l}\text { Hepatitis } \\
\text { grade }\end{array}$ & $\begin{array}{l}\text { Fibrosis } \\
\text { grade }\end{array}$ \\
\hline $\mathbf{M}$ & 12 & 1978 & 1190 & 2811 & 173 & 3 & 3 \\
\hline \multirow{3}{*}{$\mathbf{F}$} & 18 & 1985 & 1040 & 833 & 59 & 3 & 4 \\
\hline & 9 & 1978 & 11600 & & 57 & 1 & 1 \\
\hline & 16 & 1985 & 2000 & 2166 & & 1 & 2 \\
\hline \multirow[t]{2}{*}{$\mathbf{F}$} & 10 & 1978 & 4800 & & 70 & i & 2 \\
\hline & 17 & 1985 & 5000 & 3428 & 75 & 3 & 3 \\
\hline \multirow[t]{2}{*}{$\mathbf{M}$} & 27 & 1977 & 10600 & & 73 & 1 & 1 \\
\hline & 35 & 1985 & 2340 & 1600 & 26 & 3 & 3 \\
\hline \multirow[t]{2}{*}{$\mathbf{M}$} & 21 & 1979 & 15000 & 2450 & 157 & 3 & 2 \\
\hline & 27 & 1985 & 1650 & 1250 & 31 & 3 & 3 \\
\hline
\end{tabular}

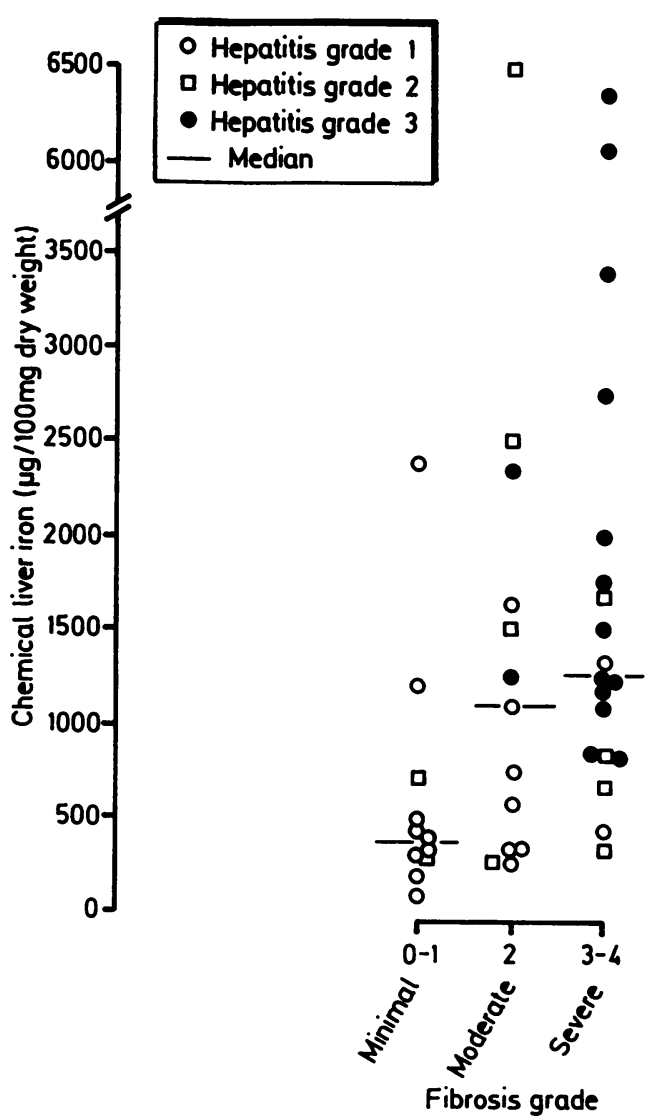

Fig 3 Relation between chemical liver iron content, hepatitis, and severity of fibrosis.

tients there was no progression of fibrosis - grade 1 (n $=1)$, grade $2(n=4)$, grade $3(n=5)$, and grade 4 $(\mathrm{n}=1)$; one showed an improvement (from grade 3 to 2) while five showed progression of fibrosis (table 6 ). In one of these five (aged 16 years) the progression was from grade 1 to 2; three (aged 17, 27, and 36 years) progressed to grade 3 from grades 2, 2, and 1, respectively, and one aged 18 years from grade 3 to 4 (cirrhosis). All these latter four patients showed 
severe hepatitis on histological examination with persistently raised serum AST values, but only one was grossly iron overloaded (chemical liver iron $3428 \mu \mathrm{g} / 100 \mathrm{mg}$ dry weight).

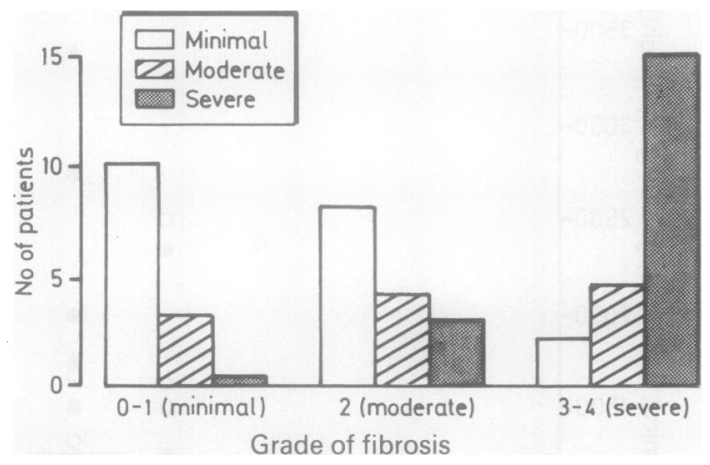

Fig 4 Details of histological hepatitis grade in relation to fibrosis grade in 49 patients (minimal $=1$, moderate $=2$, severe $=3$ ).

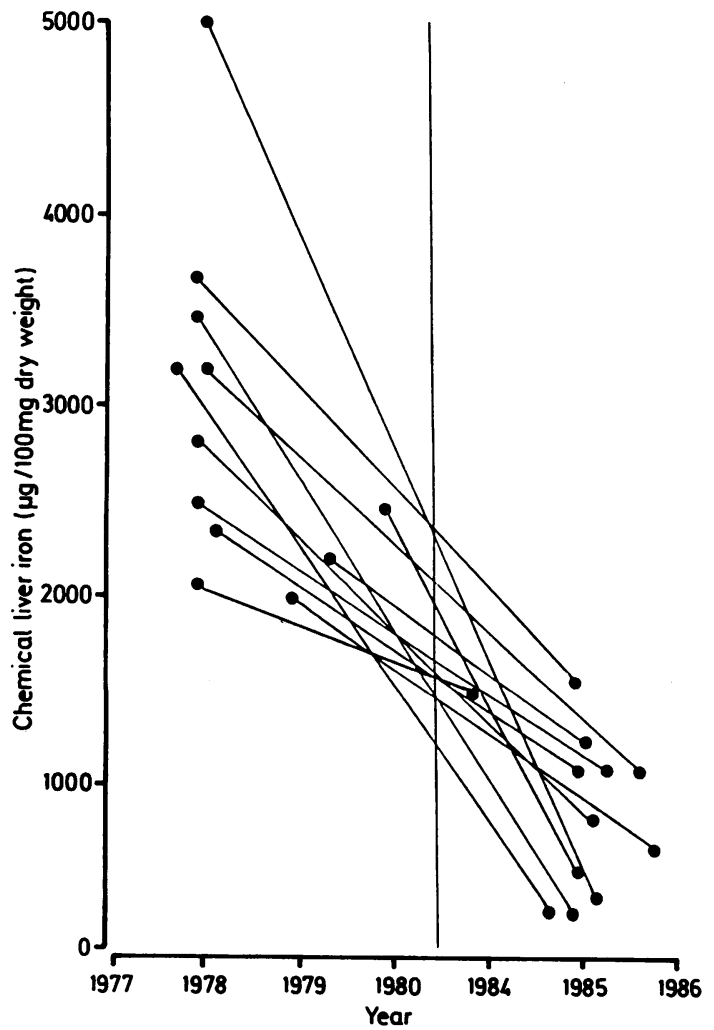

Fig 5 Chemical liver iron changes in 12 patients receiving subcutaneous desferrioxamine since 1978.

\section{Discussion}

The two important causes of liver damage in regularly transfused patients with $\beta$ thalassaemia are iron overload and hepatitis after transfusion. With regular iron chelation treatment the degree of iron overload was greatly reduced in most of our patients, and in most of them chemical liver iron content was less than 2230 $\mu \mathrm{g} / 100 \mathrm{mg}$ dry weight - the threshold at which fibrosis and cirrhosis occur in genetic haemochromatosis. ${ }^{15}$ Mean serum ferritin and liver iron concentrations were maintained at about five and 10 times the normal value, respectively. As in previous studies $^{5}$ a good correlation was found between histological and chemical liver iron assessment. The finding that serum ferritin and chemical liver iron values did not correlate with the age of patients may be partly attributed to differences in compliance of patients, as some of the oldest patients had very low values and vice versa, but it also suggests that with adequate chelation there is no increase of iron load with increasing number of transfusions, as occurs in unchelated patients. ${ }^{6}$

Post-transfusion hepatitis (due to HB or non-A, non-B viruses, or a combination) remains a major problem in these patients. Severe hepatitis assessed histologically strongly correlated with increased fibrosis in the whole group, and four of five patiento showed histological features of severe hepatitis where fibrosis increased while receiving subcutaneous des ferrioxamine for six to eight years. A similar observation was reported by Masera et al. ${ }^{2}$ Patients with severe hepatitis also had significantly increased chemical liver iron content compared with those with moderate or no hepatitis, and this was more than could be anticipated from their serum ferritin values. De Virgilis $e t a l^{5}$ also observed increased hepatic iron content in patients with thalassaemia major and chronic active hepatitis and siderosis compared with those with siderosis alone, and found no correlation of liver iron with number of units transfused. The explanation of this higher liver iron content in the face of hepatitis is unclear, but the finding suggests that severe hepatitis may contribute to liver damage by both the chronic inflammatory process and by a higher liver iron content. Our finding that liver iron in patients with severe fibrosis (grades 3 and 4) was significantly higher than in those with minimal fibrosis (grades 0 and 1) may have resulted from the fact that most of the patients with severe fibrosis had severe hepatitis (fig 3). The overall correlation of fibrosis with hepatitis was greater than it was with chemical liver iron content but clearly both factors (hepatitis and iron overload) may contribute to the liver damage.

Raised serum AST also correlated better with the 
presence of hepatitis assessed histologically, than with degree of iron overload (table 3), although seven of eight patients whose AST activity remained abnormal on eight years' follow up had both severe hepatitis and gross iron overload. Normal AST activities, however, did not exclude the presence of severe hepatitis.

About $50 \%$ of patients with moderate or severe hepatitis had antibodies in serum to hepatitis B virus components, although none had $\mathrm{HBs}$ or $\mathrm{HBc}$ antigens in the liver. These data indicate previous $\mathrm{HBV}$ infection, most probably acquired by blood transfusion. It seems likely that continuing hepatitis is related more to non-A, non-B virus infection that also stems from blood transfusions.

Only five of 51 patients were found to have fully developed cirrhosis while 16 had severe fibrosis. The mean age of these 21 patients was 20.6 years. The incidence of severe fibrosis was therefore less, and in an older age group than previously reported by Jean et $a .^{3}$ These authors studied 86 liver biopsy specimens from patients in northern Italy in the years 1976-1981 who were receiving intramuscular desferrioxamine and subsequently subcutaneous desferrioxamine. In our study deterioration of liver fibrosis seemed to be more related to hepatitis incurred as a result of transfusion than to iron overload.

The fact that patients with minimal fibrosis were significantly younger than those with moderate or severe fibrosis may have been due to the differences in the time excess iron had been present but also to the effect of earlier chelation in the younger group. Interestingly, both patients with normal liver iron concentrations started subcutaneous desferrioxamine shortly after blood transfusions began.

In conclusion, early and continuous chelation is clearly effective in decreasing liver iron overload and delaying the onset of iron induced liver damage in patients with thalassaemia. Parenterally transmitted hepatitis, however, seems to be an important factor in the progression of liver cell damage and fibrosis. The reason for the association of increased hepatic iron with hepatitis found in this study is still unexplained. The serum ferritin concentration gave an overall indication of liver iron content, but in patients with severe hepatitis changes the serum ferritin was disproportionally low. Serum AST activity correlated better in this well chelated group with severity of hepatitis rather than with liver iron content.
This study was supported by the United Kingdom Thalassaemia Society. We also thank Mrs Jackie Wilkinson, Mrs Megan Evans, and Mrs Leela Ghandi for word processing.

\section{References}

1 Risdon RA, Barry M, Flynn DM. Transfusional iron overload: the relationship between tissue iron concentration and hepatic fibrosis in thalassaemia. $J$ Pathol 1975;116:83-95.

2 Masera G, Jean G, Cazzola G, Movakova M. Role of chronic hepatitis in development of thalassaemia liver disease. Arch Dis Child 1976;51:680-5.

3 Jean G, Terzoli S, Mauri L, et al. Cirrhosis associated with multiple transfusions in thalassaemia. Arch Dis Child 1984;59:67-70.

4 Morani GA, Piacentini G, Tenzoli S, Jean G, Masera G. Hepatitis B or non-A, non-B virus infection in multitransfused thalassaemic patients. Arch Dis Child 1984;59:1127-30.

5 De Virgilis S, Cornacchia G, Sanna G, et al. Chronic liver disease in transfusion dependent thalassaemia. Liver iron quantitation and distribution. Acta Haematol 1981;65:32-9.

6 Barry M, Flynn DM, Letsky EA, Risdon RA. Long term chelation therapy in thalassaemia major: Effect on liver iron concentration, liver histology and clinical progress. $\mathrm{Br}$ Med $\mathrm{J}$ 1974;2:16-20.

7 Hussain MAM, Flynn DM, Green N, Hussein S, Hoffbrand AV. Subcutaneous infusion and intramuscular injection of desferrioxamine in patients with transfusional iron overload. Lancet 1976;ii:1278-80.

8 Propper RD, Cooper B, Rujo RR, et al. Continuous subcutaneous administration of desferrioxamine in patients with iron overload. N Engl J Med 1977;297:418-23.

9 Hoffbrand AV, Gorman A, Laulicht M, et al. Improvement in iron status and liver function in patients with transfusional iron overload with long term subcutaneous desferrioxamine. Lancet 1979;:947-9.

10 De Virgilis S, Cossu P, Sanna G, et al. Iron chelation in transfusion dependent thalassaemia with chronic hepatitis. Acta Haematol 1983;67:49-56.

11 Cohen A, Martin M, Schwartz E. Depletion of excess liver iron stores with desferrioxamine. Br J Haematol 1984;58:369-73.

12 Barry M, Sherlock S. Measurement of liver iron concentration in needle biopsy specimen. Lancet 1971;i:100-3.

13 Addison GM, Beamish MR, Hales CN, Hodgkins M, Jacobs A, Llewellin P. An immunoradiometric assay for ferritin in the serum of normal subjects and patients with iron deficiency and iron overload. J Clin Pathol 1972;25:326-9.

14 Goodall AH, Meek FL, Waters JA, Miescher GC, Janossy G, Thomas HC. A rapid one step radiometric assay for hepatitis B surface antigen utilising monoclonal antibodies. $J$ Immunol Methods 1982:52:167-74.

15 Bassett ML, Halliday SW, Powell LW. Value of hepatic iron measurements in early haemochromatosis and determination of the critical iron level associated with fibrosis. Hepatology 1986;116:83-95.

Requests for reprints to: Professor AV Hoffbrand, Department of Haematology, The Royal Free Hospital, Pond Street, Hampstead, London NW3 2QG, England. 